\author{
MARÍA DE LOURDES NAVARIJO ORNELAS
}

INSTITUTO DE BiOLOGÍA, UNAM

\title{
Arte y ciencia a través de las imágenes de aves en la pintura mural prehispánica
}

n el emento iconográfico constante en el arte prehispánico son las imágenes de aves, en razón de que éstas se encuentran de manera reiterada en la arquitectura, en la cerámica y en la pintura mural de numerosos sitios arqueológicos a lo largo y ancho del territorio nacional.

¿Cuál es el significado de esa presencia constante? En un primer nivel la respuesta se encuentra en que la presencia de diferentes especies de aves constituye en sí misma una prueba de la importancia cultural que se les otorgó, puesto que las aves están referidas a un dato arqueológico. Esto implica, en otras palabras, que al estar en un muro pertenecen a un sitio en particular y, por tanto, corresponden a una cultura que dejó distintos testimonios de su manera de pensar y de sentir a través de la expresión plástica en un momento de su historia.

En consecuencia y como un segundo punto está el hecho irrefutable de que estas imágenes de aves son parte de un lenguaje pictórico, el cual, las más de las veces, es de carácter metafórico. Sin embargo, la pintura mural como legítima expresión plástica goza de valor artístico en donde las imágenes sustentan los conceptos. Sobre este aspecto es de interés retomar lo que Elías Trabulse sostiene en sus análisis históricos sobre arte y ciencia, pues

I. Elías T rabulse, Arte y ciencia en la historia de M éxico, M éxico, Fomento Cultural Banamex, I995, p. I7. 
DOI: http://dx.doi.org/10.22201/iie.18703062e.2000.77.1945

6

MARÍA DE LOURDES NAVARIJO ORNELAS

"por extraño que pueda parecer, es precisamente a través del arte que la ciencia configura su propia historia ya que sin imágenes la ciencia sería inexplicable". Y si bien mucho se ha discutido acerca de la existencia o no de una ciencia prehispánica, por carecer ésta de un método científico, no deja de ser relevante la circunstancia de contar con un nutrido catálogo de especies representadas en la pintura mural prehispánica.

Este planteamiento nos conduce a un tercer punto de gran interés, es decir, el concerniente a la diversidad de especies de aves involucradas en la pintura mural. En efecto, no se trata de un ave en exclusiva sino de varias especies las que figuran en las diferentes escenas, ya que convergen diversas aves acuáticas, aves de presa diurnas y nocturnas, guacamayas y loros, palomas, colibríes y otras. D icha diversidad es un indicador de que la efigie de una determinada ave no sólo puede ser vista como parte de una obra artística, porque esa misma diversidad también lo es de la estrecha relación que existiera con el medio, debido a que esa relación influyó de muchas maneras en los procesos culturales. De esta suerte la fisonomía del ave, el color de su plumaje, su comportamiento y el ambiente físico en el que se desenvuelve tuvieron un peso definitivo en la estructuración del lenguaje pictórico.

Es incuestionable que esa diversidad de especies formó parte sustancial del repertorio de conceptos religiosos y filosóficos, así como de los sucesos políticos y sociales más relevantes. Basta con revisar algunos murales para constatar que un número considerable de aves fue seleccionado, de entre la gran variedad de estímulos visuales que proporciona el ambiente natural de modo preferente, como el instrumento más apropiado para su representación simbólica.

Asimismo, no debe quedar de lado que el análisis de las imágenes denota un cúmulo de conocimientos de índole morfológica y conductual propios de cada especie, amén de estar implícita una referencia directa al ambiente físico. Este tipo de acontecimientos permite hablar de las aves no sólo como parte de una iconografía del arte prehispánico, sino que al mismo tiempo obvia la existencia de una singular iconografía avifaunística, porque, después de todo, las aves son las protagonistas del reto de transformar creencias y sucesos en imágenes concretas para narrar una historia de tonalidades diversas en los murales.

Por consiguiente, y desde mi punto de vista, la importancia de las aves representadas en la pintura mural prehispánica reside en que constituyen un registro verídico de la diversidad de especies conocidas y valoradas. Del 
mismo modo, este registro gráfico provee de información detallada sobre los conocimientos de morfología y sobre los hábitos de cada especie, lo que faculta para establecer, de acuerdo con lo mencionado por Trabulse, "una nueva inteligibilidad de la realidad, a la vez empírica y artística".

En función de lo expuesto en los párrafos anteriores, la finalidad de esta contribución es la de examinar, con base en el inventario de especies de aves representadas en la pintura mural de Teotihuacan y de cinco sitios arqueológicos de la zona maya, las modalidades en la representación gráfica; si bien al mismo tiempo se busca plantear, aunque de forma general, los argumentos que auxilien en la explicación del papel de las aves en el complejo lenguaje pictórico aludiendo a las cualidades particulares de cada especie.

\section{Realidades y abstracciones}

En numerosas muestras de pintura mural se observan en distintas posiciones cabezas, picos, alas, colas y patas que denuncian la presencia de un ave. Estas aves son presentadas de dos maneras básicas: en actitudes con carácter naturalista o revestidas de atributos sobrevalorados y simbólicos. En ambas situaciones se puede llegar a encontrar un equilibrio entre la naturalidad de las formas y las fórmulas metafóricas, ya que, a pesar de las estilizaciones vinculadas con el diseño, los rasgos que distinguen a una especie 0 un patrón de conducta en particular fueron exaltados sobre otros caracteres, lo que permite veladamente su identificación genérica. Al respecto, es conveniente recordar la propuesta de $\mathrm{M}$ arta Foncerrada de M olina³ sobre los motivos estudiados en Teotihuacan, pues en este sentido señala que "los cambios en el manejo de la forma natural están imbricados en el desarrollo histórico de la organización político-religiosa y del ritual teotihuacanos". Por consiguiente, el manejo de las formas naturales involucra un juego de valoración y de equiparación de cualidades entre la condición y acciones humanas y las aves como instrumentos simbólicos.

La mayoría de los organismos representados son mostrados con sus rasgos fisonómicos más distintivos, lo que permite distinguirlos de otras especies.

2. I bidem, p. 2I.

3. M arta Foncerrada de M olina, "La representación de pájaros en el arte teotihuacano", en A nales del Instituto de InvestigacionesE stéticas, vol. xv, núm. 57, M éxico, 1989, p. 7. 
DOI: http://dx.doi.org/10.22201/iie.18703062e.2000.77.1945

Así, un mismo carácter, como el pico, fue recreado hábilmente de diferentes formas. Un pico largo, delgado y afilado como espina distingue a un colibrí, mientras que un pico ganchudo y de aspecto fuerte sugiere, casi siempre, que se trata de un ave rapaz y, sin duda, un pico que muestra una gran abertura y un saco glandular expandido acusan la presencia de un pelícano. D e manera similar, en los murales quedaron consignadas las características de las patas y pies con sus respectivas diferencias funcionales, pues nunca se hizo uso de un ave acuática para representar las acciones de trasladar objetos con las patas, ya que aves como los pelícanos, los flamencos o los patos, al ser aves que nadan o que vadean, suelen tener dedos unidos, al menos hasta cierto grado, por membranas, o bien los dedos son lobulados y no aptos para la sujeción de objetos. Para dicho fin tampoco se puede pensar en los pies sumamente pequeños y débiles de golondrinas, vencejos y colibríes. Entonces, para representar de modo particular una acción de movimiento y transporte con los miembros inferiores, aves como los caracara, águilas, búhos y otras rapaces fueron seleccionadas por sus pies con dedos muy potentes y separables con amplitud que les permite sujetar y llevar a sus presas (véase más adelante el caso de las "aves en procesión" de Totometla, en Teotihuacan).

Tomando en cuenta que las aves fueron tratadas con naturalidad, o bien que lo fueron concediéndoles atributos simbólicos específicos, se puede deducir que como parte de la preparación o formación de los pintores privaron necesariamente los conocimientos de historia natural. Este acervo fue conjugado en diferente medida con las ideologías y simbolismos, aun cuando no deja de ser una realidad, como condicionante en cada una de las creaciones, la destreza propia del o de los artistas, así como el grado de percepción que se tuviera sobre las aves elegidas.

Poder recrear diferentes imágenes de aves con sus características distintivas, pero inmersas en un lenguaje simbólico, representa una serie de inconvenientes. Entre ellos destaca el movimiento continuo de los organismos, el cual repercute en las oportunidades reales de observación y, por ende, en la retención de los detalles, a lo que se suman las dificultades que trae consigo la ubicación de los sitios de percheo y de alimentación donde las aves pueden ser vistas; también constituyen un problema para el observador los reflejos de luz que inciden sobre el plumaje y la talla del ave. 4 D esde luego que, aunado a estos aspectos, hay que tener presente que la intención al dibujar un ave 
DOI: http://dx.doi.org/10.22201/iie.18703062e.2000.77.1945

ARTE Y CIENCIA A TRAVÉS DE LAS IMÁGENES DE AVES

nunca fue la de lograr una imitación minuciosa ni reproducirla bajo cánones descriptivos; más bien se puede decir que se seleccionaron y privilegiaron ciertos rasgos que de manera directa correspondían a los propósitos de la composición. 5 Esta coyuntura hace que la imagen recreada posea una doble función, pues, además de ser un elemento gráfico, ofrece un respaldo para el mensaje pictórico, dada la fuerza de las composiciones.

Partiendo del hecho de que las aves fueron representadas parcialmente (sólo la cabeza, cabeza y patas, en tres cuartos) o con el cuerpo completo, para su estudio he reconocido tres modalidades básicas en la representación, contando con una cuarta para reunir los fragmentos para su estudio sistemático (cuadro I). Cabe señalar que en otra oportunidad ${ }^{6}$ presenté una primera versión sobre esta propuesta de análisis.

I. En una escena se observa un solo individuo y, por tanto, una sola especie de ave, como en el caso de la guacamaya verde que figura en el Corredor I5, M ural i en Tetitla, Teotihuacan (figura I); una garza morena en posición de vuelo en picada en el centro de la escena conocida como "aldea maya a orillas del mar", o como complemento del dios de la muerte un milano fue dibujado en la zona basal exterior del lado norte del Templo de los Guerreros en C hichén Itzá, Yucatán.

II. M ás de una representación gráfica en la escena, pero una sola especie de ave. Ejemplo de ello lo tenemos en el Cuarto 22 de Tetitla donde se aprecian dos zopilotes o auras; los caracara o quebrantahuesos pintados en el Pozo I2, cuadros I, 2 y 3, Y, J y K en el sitio Purificación-Pirámide, denominado también Totometla; la sucesión de loros (I7 individuos) representados de perfil en un tablero de la Zona 2, Templo de los Caracoles Emplumados, Subestructura 2, en Teotihuacan (figura 2).

III. Por último, en la escena pueden figurar varios individuos de aves que pertenecen a diferentes especies. Los casos más ilustrativos son las dos especies de paloma recreadas en el Mural 2 del Cuarto i en la Zona 4, Ani-

hispánica en M éxico, M éxico, U niversidad N acional Autónoma de M éxico, Instituto de Investigaciones Estéticas, vol. II, Área maya, t. III, Estudios, 200I, pp. 22I-253.

5. Ibidem.

6. N avarijo, "Por qué es de utilidad conocer la identidad de las aves representadas en la pintura mural prehispánica", en Coloquio C antos de M esoamérica. M etodologías científicas en la búsqueda del conocimiento prehispánico, M éxico, Universidad N acional Autónoma de M é xico, Instituto de Astronomía, Facultad de Ciencias, 1995, pp. 315-322. 
DOI: http://dx.doi.org/10.22201/iie.18703062e.2000.77.1945

IO MARÍA DE LOURDES NAVARIJO ORNELAS

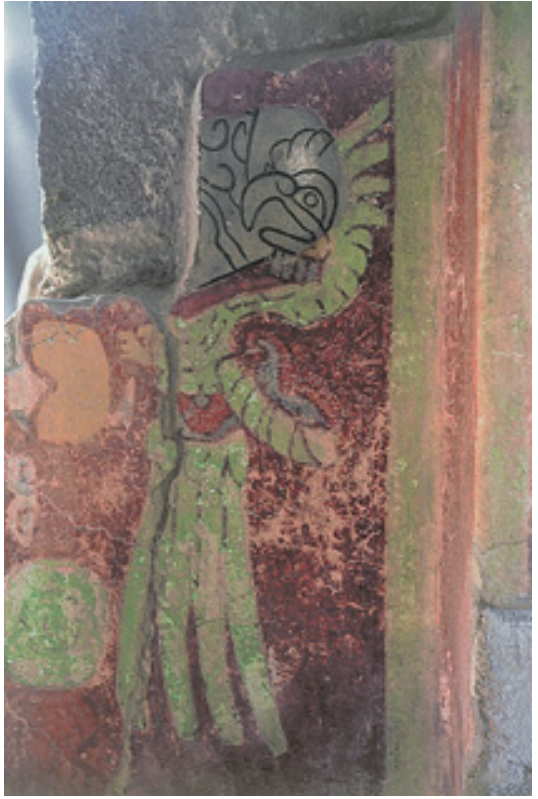

Figura i. De cuerpo entero una guacamaya verde (Ara militaris) se observa en el M ural I, Corredor is en Tetitla, Teotihuacan. Foto: Eduardo A. Cerezo.

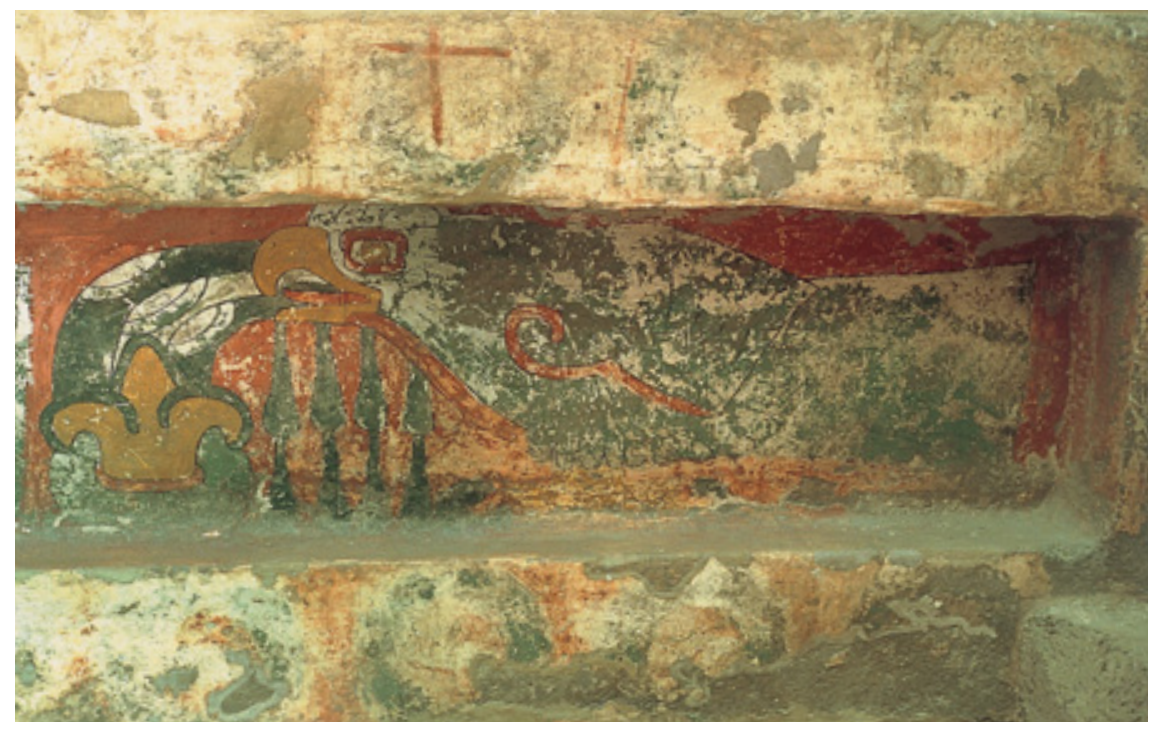

Figura 2. En un tablero de la Zona 2 correspondiente al Templo de los C aracoles Emplumados figuran i7 loros (Amazona albifrons). Foto: Pedro Cuevas. 
Figura 3. En posiciones animadas, dos espe cies de paloma se encuentran en el Mural 2 del Cuarto I, Plataforma i, en la Zona 4 llamada "Animales M itológicos". Foto: Eduardo A. Cerezo.

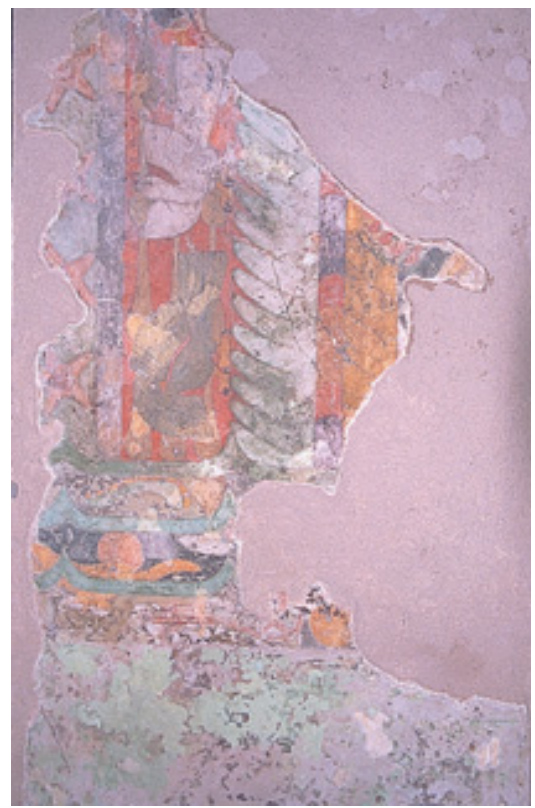

males M itológicos, en Teotihuacan (figura 3); los dos loros y siete guacamayas rojas del mural I, Los pájaros, en Xelhá, Q uintana Roo, y las cinco especies de aves con por lo menos I6 individuos en la Estructura I de Xuelén, Campeche.

Aunados a estos tres niveles de representación gráfica y de acuerdo con los análisis efectuados, de igual forma he identificado cinco niveles de integración temática (cuadro I), puesto que en el discurso pictórico las aves figuran de manera independiente 0 en la composición forman parte de:

a. Alguno de los objetos representados, como lo es una tapadera de un recipiente 0 especie de vasija en forma de una cabeza de búho situada a los pies de una figura sedente de perfil plasmada en el Cuarto 27, Mural i en Tetitla, Teotihuacan (figura 4 ). Se trata de un búho de acuerdo con la hechura y posición de los ojos, el pico y la disposición de las plumas a ambos lados de la cabeza; los asideros del recipiente simulan un par de orejas.

b. Las aves forman parte de los elementos que integran la vestimenta al ser parte de los disfraces empleados o en función del uso que se hiciera de las plumas para la confección de las variadas prendas, como se observa en ciertos personajes teotihuacanos. 
12

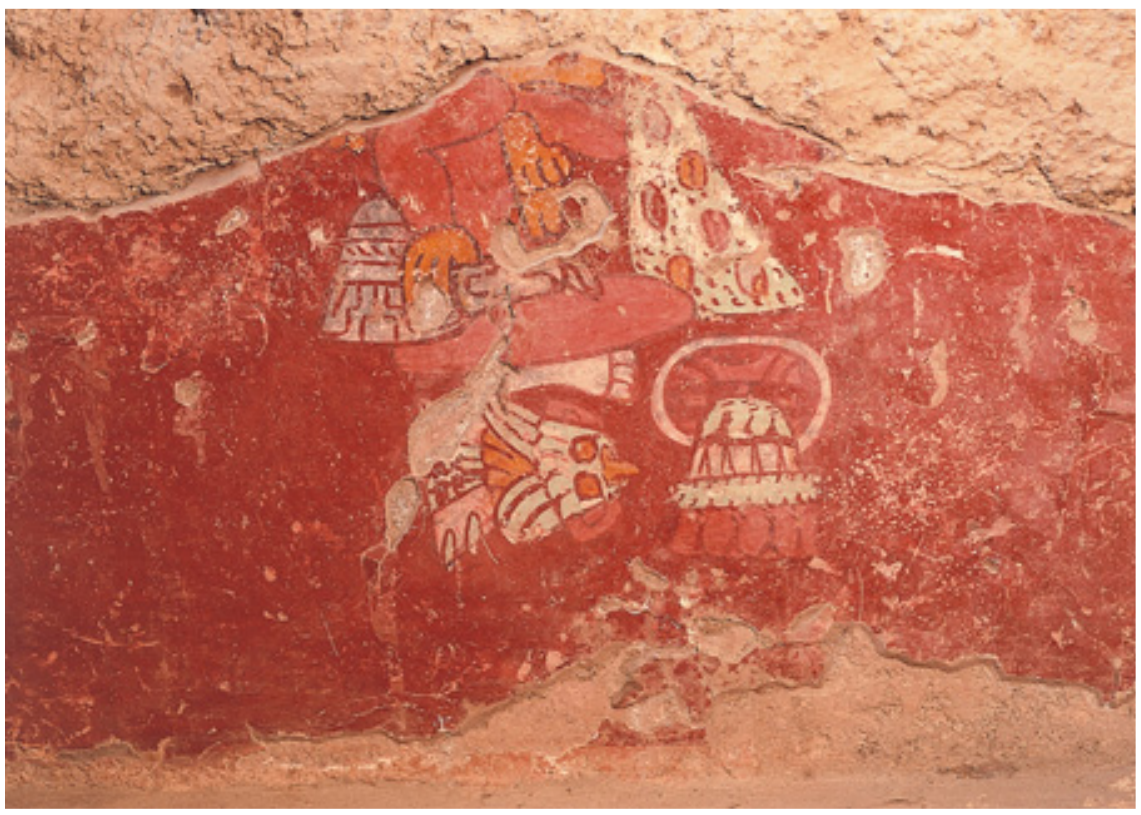

Figura 4. Un objeto con forma de cabeza de búho fue situado a los pies de un personaje sedente en el M ural I del C uarto 27 en T etitla, T eotihuacan. Foto: Pedro Cuevas.

c. Toda el ave o partes de ella forman parte de un tocado: como el colibrí de cuerpo completo que aparece en el M ural i conocido como Los sacrificadores en la Estructura A del sitio de M ulchic; o las tres cabezas de ave con el pico entreabierto que son parte de los elaborados tocados que pertenecen a dos sacerdotes que figuran en los murales de la Zona II, Gran Conjunto, en Teotihuacan (figura s).

d. Como individuos autónomos también es posible reconocer a las aves, si bien esto puede ser de una manera complementaria dentro de los elementos que integran la escena: como el pelícano dibujado en los murales I, 4 y 5 del Cuarto iz en el Conjunto del Sol en la Zona 5 A, en Teotihuacan, donde además podemos ver varias cabecillas de ave (figura 6).

e. Por otra parte, en una escena el o los individuos de aves constituyen el tema central, por lo que se les puede considerar como los principales personajes. Tal es el caso de las aves de Xuelén, de Xelhá, las águilas de Tetitla que se distribuyen en el Pórtico 25, M urales 3-6; Patio 25, M ural 25, y Corredor 25, Mural 7, o bien en Atetelco las aves de cuerpo completo parecidas a 


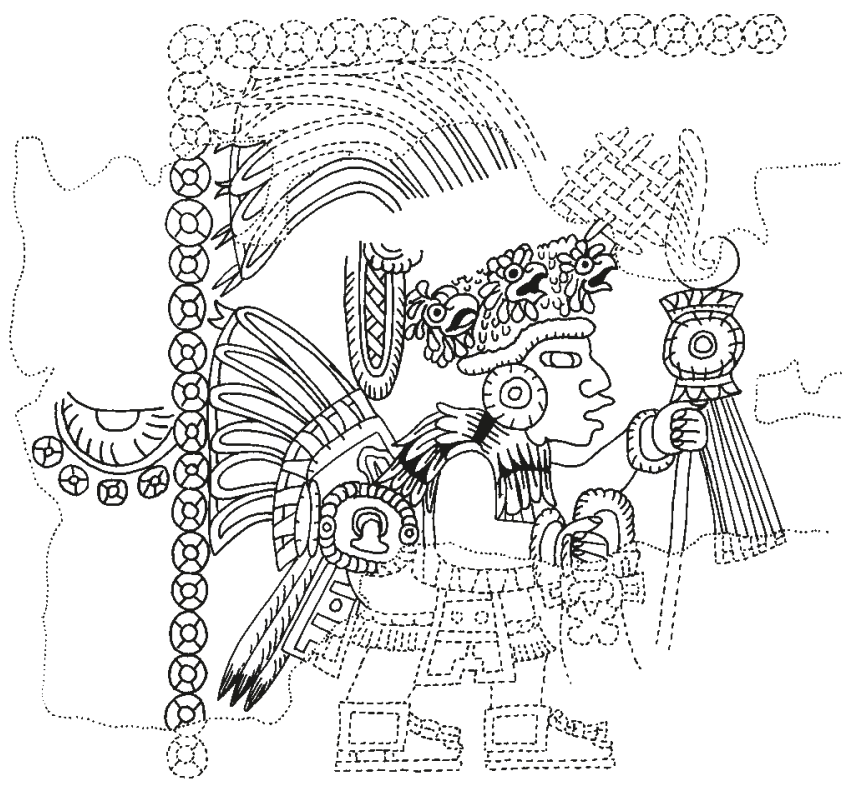

Figura 5. T res pequeñas cabezas de aves que muestran el pico entreabierto. Son parte de un elaborado tocado que porta un sacerdote que fue reconocido en el Cuarto I, M urales I-2, de la Zona II, Gran Conjunto, en Teotihuacan. M iller, I973.

águilas sobre un pedestal, situadas en el Patio Norte 0 Patio 3, Pórtico I, Murales 2-3.

La información contenida en el cuadro i señala básicamente que, de las tres modalidades propuestas, la tercera sobresale hasta este momento, ya que varios individuos de aves que pertenecen a diferentes especies figuran de modo predominante sobre aquellas representaciones en donde sólo hay una especie (modalidad I con siete casos estudiados), o bien la de varios ejemplares de una especie (modalidad in con seis casos). En una primera instancia este resultado denota la importancia de las aves como elementos iconográficos, pues las tres modalidades fueron cubiertas. Por otra parte, esta información también hace manifiesta la existencia de una preferencia selectiva destinada a cubrir las diferentes necesidades de carácter naturalista o las de contenido metafórico al elegir una o varias especies de aves en relación con otros grupos animales. 


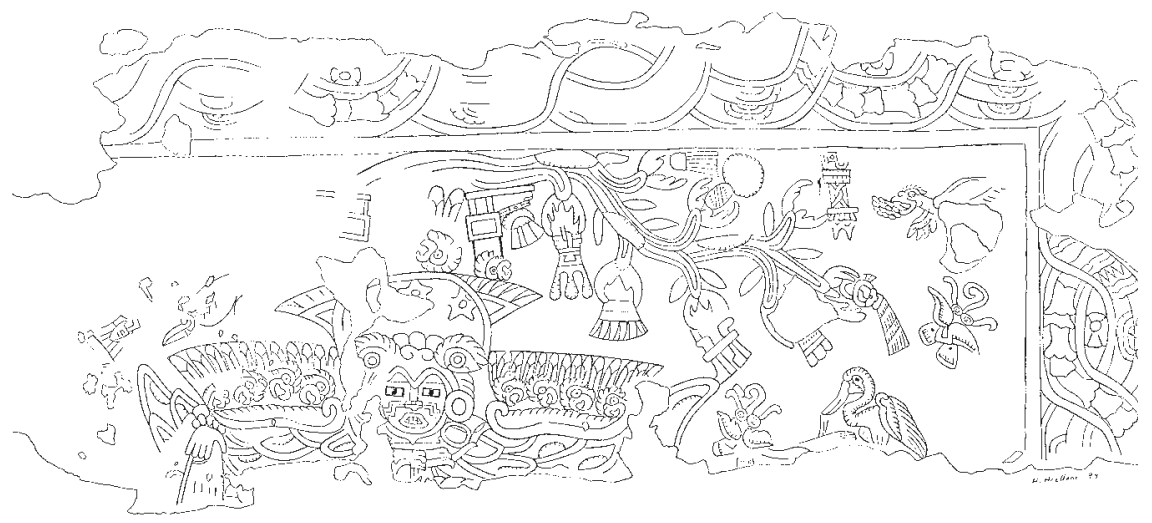

Figura 6. En el Cuarto I3, M urales I, 4 y 5 del Conjunto del Sol perteneciente a la Zona 5 A se puede apreciar la imagen de un pelícano como elemento complementario en la escena. D ibujo: Alfonso Arellano.

En cuanto a los niveles de integración temática, los análisis practicados indican que las aves como individuos independientes aparecen de manera equitativa como elementos que complementan una escena, o bien como los elementos iconográficos que constituyen el tema principal del mural, esto es, I7 casos detectados respectivamente (cuadro I). Sin embargo, cabe apuntar que pueden surgir algunas modificaciones numéricas conforme se avance en los exámenes de otros murales, pero ello no obsta para que de nueva cuenta sea ratificada la importancia de las aves en el discurso pictórico de acuerdo con el simple hecho de haber podido definir, hasta el momento, cinco categorías en el análisis.

\section{Imágenes y contextos}

Los beneficios de conocer la identidad biológica de las diferentes especies de aves que se encuentran en la pintura mural residen, principalmente, en las posibilidades que se abren para trabajar en la comprobación de los estudios disponibles hasta la fecha. No obstante, al mismo tiempo, la identificación taxonómica de una determinada ave, como parte del conjunto de elementos iconográficos reunidos en una misma escena, coadyuva a complementar la 
lectura al dar otro peso a los procesos de esclarecimiento de los porqués de esa presencia y de su relación con los otros elementos. Además, al conocer la identidad biológica se cuenta con otros cimientos para el planteamiento de nuevas interpretaciones iconográficas que derivan en diversas propuestas que enriquecen la información existente.

Aunado a estas tres posibilidades de investigación, otro punto que no ha sido considerado totalmente es el vinculado con la inestimable información biológica que cada imagen de ave puede proveer. El examinar desde el punto de vista biológico las imágenes es de importancia porque, entre otros aspectos, se carece de fuentes para concertar una aproximación con el universo de conocimientos de historia natural existentes en el mundo prehispánico.

Tomando en cuenta estos eventos y conforme a los objetivos previstos de contar con un inventario de especies que nos informen sobre las implicaciones simbólicas de las aves, se presentan en el cuadro 2 las dieciocho especies determinadas hasta este momento, más diez aves reconocidas sólo a nivel genérico; esto hace que se cuente en total con quince familias de aves. Las diversas especies que integran este cuadro son un reflejo de la estima gestada hacia las aves al convertirlas en un fértil recurso iconográfico bien conocido y valorado para poder ser incorporado en las expresiones pictóricas. Su representación fue lograda con tendencias naturalistas más que simbólicas, y sólo en un nivel contextual es que se puede juzgar la calidad y cantidad de atributos simbólicos conferidos a cada imagen.

Antes de adentrarnos en la exposición de algunos de los casos estudiados, es oportuno dejar asentado que el análisis de la identidad taxonómica de las aves teotihuacanas y mayas ya fue dado a conocer en tres obras que anteceden a esta contribución, y que son producto de los estudios realizados dentro del Seminario de la Pintura M ural Prehispánica en M éxico que coordina Beatriz de la Fuente. Por este motivo, estimo que la revisión de unos ejemplos es suficiente para poder advertir la riqueza de especies y para apreciar conjuntamente la calidad artística de las representaciones.

Siguiendo la propuesta contenida en el cuadro i respecto a las modalidades de representación gráfica y de integración, se tiene que, de entre las dieciséis aves reconocidas en el Cuarto i o Sur de la Estructura i en el sitio de Xuelén, C ampeche, tres de ellas corresponden a imágenes de la esbelta ave acuática que mide $850 \mathrm{~mm}$, y que es conocida como anhinga americana, también llamada pato aguja o pato serpiente (Anhinga anhinga; figura 7 ). D ebido a que en el mural se encuentran al ternados varios individuos de aves 


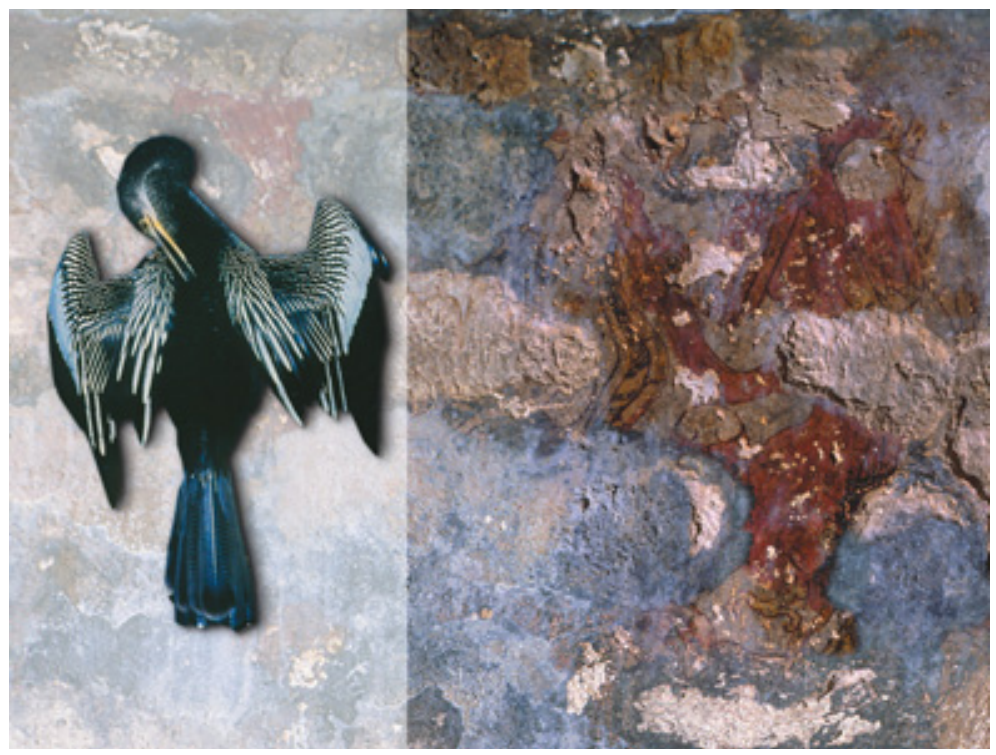

Figura 7. La anhinga americana es una de las cinco especies de aves que se pueden reconocer en el Cuarto i o Sur de la Estructura i en Xuelén, Campeche. Digitalización: Ricardo Alvarado.

de diferentes especies, se puede considerar de manera individual a cada uno de los cuatro grupos de aves reconocidas como el ementos que se complementan en la composición. Sin embargo, la reunión de las diferentes especies plasmadas constituye el tema central de dicho mural.

Se identifica como anhingas a tres de los individuos (los números 4, 6 y io) porque la cabeza presenta lo que parece ser un corto copete, que corresponde a las plumas laterales que posee la anhinga. También es interesante advertir, de acuerdo con la posición de las alas en las tres aves estudiadas, una coincidencia del diseño del hombro, es decir de las plumas que se distinguen en la región escapular de la anhinga. El cuello es otro rasgo notable en las representaciones, y se le puede ver de dos formas, esto es, flexionado o se observa corto porque tal vez se encuentra recogido. La explicación a esta situación se encuentra en que en la anhinga es muy largo y serpentino porque posee veinte vértebras, lo que le permite al ave curvarlo, al estar posada o volando, hasta adoptar una forma de S o de G. La cola es tiesa, larga y redondeada en la punta. El pico es afilado y finamente dentado en las dos orillas cortadoras. 
Considerando las pruebas comparativas señaladas, estas caracterizaciones pueden ser calificadas como naturalistas, si bien se deben tomar en cuenta también los argumentos conductuales y de hábitat generales. Estas aves frecuentan ríos y lagos, aunque suelen ser más abundantes en esteros, y se les puede ver posadas en las ramas 0 en los troncos cercanos al agua. Su dieta se compone principalmente de varias clases de peces, empero consumen insectos acuáticos, sanguijuelas, camarones, ajolotes, lagartijas, víboras de agua y hasta pequeños cocodrilos. ${ }^{7}$ El método de caza consiste, según Álvarez del Toro, ${ }^{8}$ en mantener el cuello recogido y bucear a gran velocidad detrás de los peces para que al tenerlos a su alcance puedan desplegar el cuello muy rápidamente para atravesarlos con el agudo pico, o bien, pueden permanecer posadas y atraer a los peces por medio de su sombra oscura, para luego lanzarse tras su presa bajo el agua. D espués de observar las posiciones y rasgos de estas tres aves, resulta admisible que este comportamiento sea el que acusan dos de las aves (la 6 y la io), ya que la número 4 parece ya haber cazado y se dispone a comer, pues se encuentra sosteniendo con el pico una especie de morena.

D e igual forma son de carácter naturalista los dos zopilotes 0 auras que se encuentran en el Cuarto 22 de Tetitla (figura 8). Éstos corresponden a la categoría de más de una representación gráfica - de una sola especie- , y son el tema central de los M urales y y 2. En forma animada cada zopilote aparece posado sobre un gran caracol, al que sostienen con el pico empleando para ello un sujetador a manera de collar. La posición adoptada al estar posados y otras particularidades como la coloración del plumaje, la aparente carencia de plumas en cabeza y cuello, y la falta de las patas, que en Cathartes aura son débiles, hacen que las imágenes en su conjunto se apeguen a la descripción de esta especie de zopilote.

En un nivel contextual resulta revelador mencionar el hecho de que se trata de una especie que carece de siringe y que, por ello, no posee voz. Es entonces interesante observar una vírgula que curiosamente no se desprende del pico, que sería lo esperado puesto que existen casos concretos de aves con vírgulas en sus picos, sino que aquí sale del caracol. Este hecho plantea que el

7. Arthur Clevaland Bent, Life Histories of $\mathrm{N}$ orth America Petrels and Pelicans and their Allies, N ueva York, D over Publications, 1964, pp. 229-236.

8. M iguel Álvarez del Toro, Las aves de Chiapas, T uxtla G utiérrez, U niversidad Autónoma de Chiapas, 1980, p. I4. 


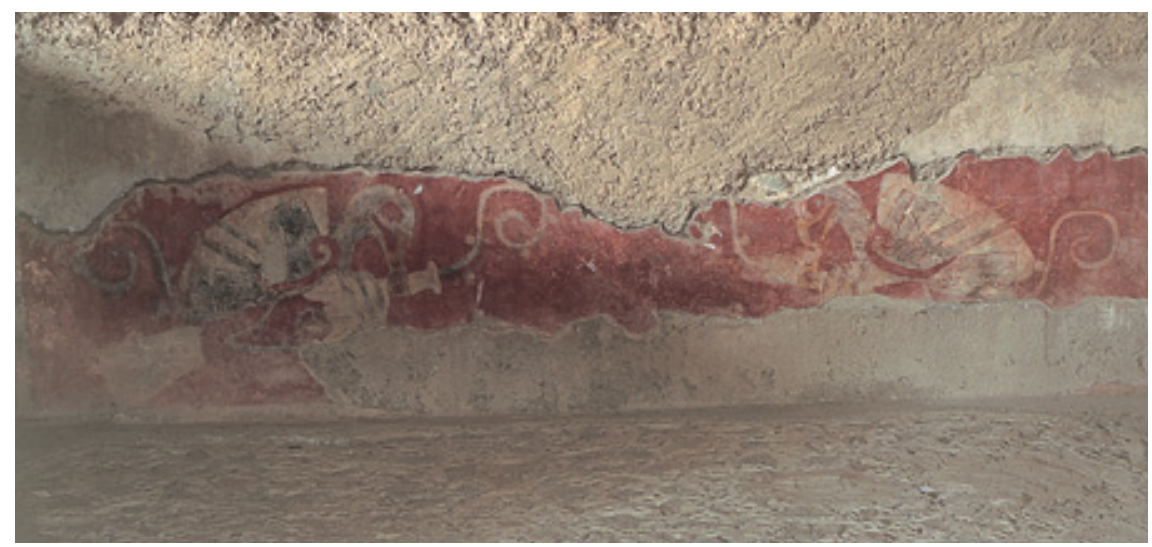

Figura 8. En los M urales i y 2 del Cuarto 22 de Tetitla, dos zopilotes posados sobre sendos caracoles constituyen el tema central. Foto: Eduardo A. Cerezo.

ave, al ser incapaz de emitir sonidos, hace uso del caracol como fuente sonora. En este caso interesa señalar que el aspecto individual tanto del ave como del caracol es sencillo y natural, siendo la composición la que confiere las condiciones alegóricas, ya que el zopilote y el caracol se complementan como elementos iconográficos.

Continuando con los ejemplos que ofrece Tetitla, Teotihuacan, en varios murales (Pórtico 25, M urales 3-6; Patio 25, Mural 25, y Corredor 25, M ural 7) se pueden apreciar singulares representaciones del águila tirana (Spizaetus tyrannus) de cuerpo completo o sólo de las cabezas (figura 9). La presencia de esta ave de presa es un modelo apropiado para constatar el equilibrio de los diseños, pues la autenticidad de la fisonomía fue convenientemente adecuada a las necesidades simbólicas para crear códigos visuales.

Con seguridad, la apariencia elegante de esta rapaz de más de medio metro, que luce un penacho y que posee una cola negra con cuatro o cinco barras pardo grisáceo y que demuestra cierta ferocidad en la persecución de sus presas, constituyó la base para que fuera vinculada con determinados actos de sacrificio. Es consecuente que un ave de presa sea mostrada con gotas de sangre o con una clase de banda que puede ser tomada como un chorro copioso proveniente de su pico. A esta situación se suma la franca disposición que tiene el ave de emprender el vuelo, ello de acuerdo con el ademán de las alas abiertas y con el no insinuarse ninguna actitud de permanecer posada. Es interesante anotar que esta águila acostumbra trazar círculos en el aire. 


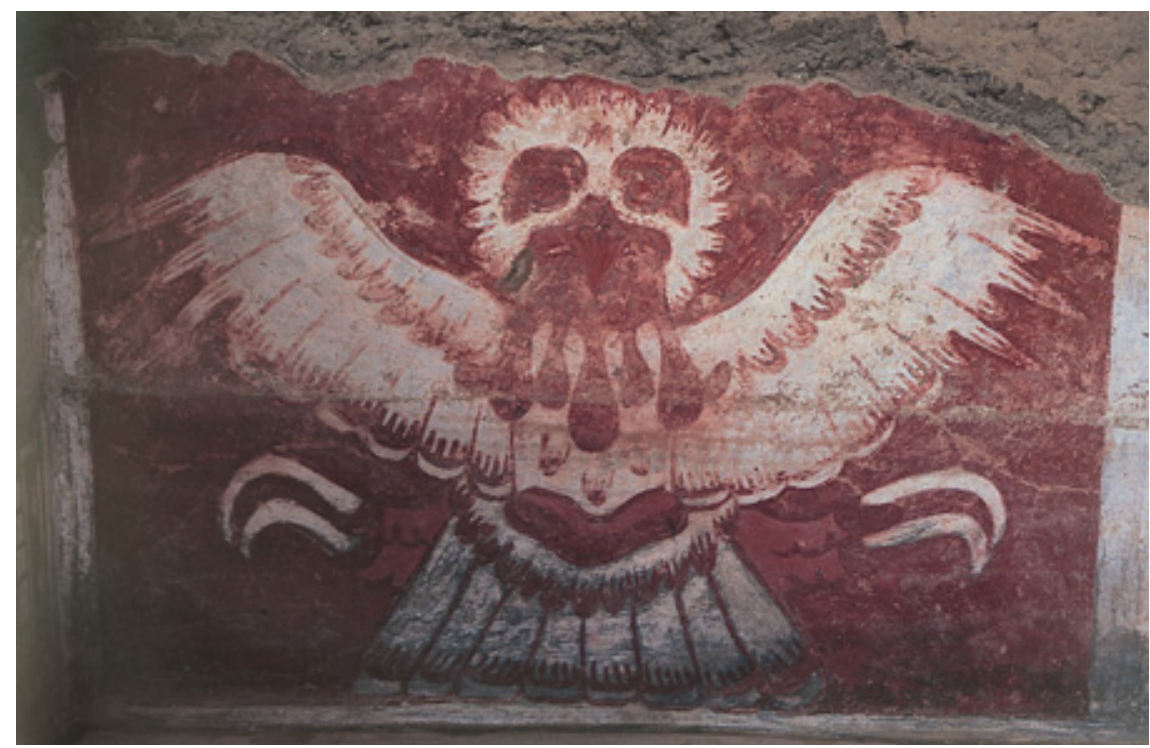

Figura 9. En varios murales del recinto de Tetitla fueron plasmadas águilas con el cuerpo completo o sólo la cabeza. Foto: Eduardo A. Cerezo.

En razón de distinguir dos tallas diferentes, es decir, águilas mayores y águilas menores con sus correspondientes atributos simbólicos (las gotas 0 chorros de sangre), se puede sugerir que su presencia obedece a motivos de índole emblemática, así como también a la referencia de una acción de sacrificio. Además, es viable la suposición en este caso de que el águila estuvo relacionada con el Sol dador de vida, ese sol que recorre su camino del alba al ocaso en un morir y renacer eternos, simbolizado por el poderoso vuelo del águila, a decir de una significación de vida-ascendente y de muertedescendente. ${ }^{9}$

Una materia utilizada ampliamente en la pintura mural fue, sin duda, el vuelo de las aves bajo diferentes grados de valoración y conceptualización. El caso de las águilas que acabamos de ver es uno de ellos; sin embargo, no en todas las situaciones fue utilizado con tendencias simbólicas, pues también

9. N avarijo, "La presencia de las aves en la pintura mural teotihuacana", en La pintura mural prehispánica en M éxico, M éxico, U niversidad N acional Autónoma de M éxico, Instituto de Investigaciones Estéticas, I996, vol. I, T eotihuacán, t. II, Estudios. 
DOI: http://dx.doi.org/10.22201/iie.18703062e.2000.77.1945

encontramos un vuelo armonioso y despreocupado en los M urales I-2 del Pórtico iz en el Conjunto del Sol en la Zona 5, en Teotihuacan. En estos murales hay unas siete aves que ocupan diferentes posiciones, y que acompañan a un jaguar delineado en azul con el rostro de frente y rodeado por una planta de maguey, mariposas y flores de cuatro pétalos. Todas las aveciIlas muestran sus al as extendidas y poseen la vírgula de la palabra como una expresión de su voz y su canto.

Por otro lado, en el Templo de los Guerreros fueron registradas por M orris y otros autores ${ }^{10}$ seis aves en dos pequeños fragmentos de mural; es probable que éstos procedan del mismo cuarto en donde estuviera plasmada la conocida escena de comercio (figuras ioa y rob). Aun cuando las dos piezas son pequeñas, se distingue a las aves con actitudes de vuelo en distintas posturas, una con respecto a la otra; esto quiere decir que no cumplen con un orden 0 una formación establecida de acuerdo con un comportamiento de grupo, como el que adoptan en su vuelo conjunto los patos o los gansos.

A primera vista, la fisonomía de estas aves deja la sensación de que no fueron dibujadas con la intención de reproducir un modelo específico, porque las posturas son hasta cierto punto irreales, y las formas en lo general son ordinarias y carentes de rasgos distintivos. Por ejemplo, en todas se puede apreciar que los ojos son redondos y simples; las colas son semihorquilladas y no muestran ninguna peculiaridad que indique su identidad. Al observarlas, lo único patente es el hecho de poder rememorar, de modo escueto, la acción de revolotear o de remontarse de una manera espontánea, ello gracias a las alas extendidas y a que en ninguna se notan las patas, que se recogen cuando el ave emprende su vuelo.

Por este motivo, estimo que debió existir una llana libertad para que el artista diera rienda suelta a su creatividad bucólica, sin las limitaciones a que pueden dar lugar los compromisos naturalistas y los de interés simbólico. También, ante estos hechos, se puede pensar que los pajarillos formaban parte de algún decorado, donde el propósito era el de enaltecer la capacidad de vuelo bajo algún tipo de concepción simbólica. ${ }^{\text {II }}$ Por último, su presencia habla al mismo tiempo del singular aprecio que existió por las aves.

Io. Earl H. M orris et al., The T emple of the W arriors at Chichén I tzá, Yucatán, W ashington, Carnegie Institution of W ashington, 1931, p. 472.

II. N avarijo, "Las aves en el mundo maya prehispánico", art. cit. 
DOI: http://dx.doi.org/10.22201/iie.18703062e.2000.77.1945

ARTE Y CIENCIA A TRAVÉS DE LAS IMÁGENES DE AVES

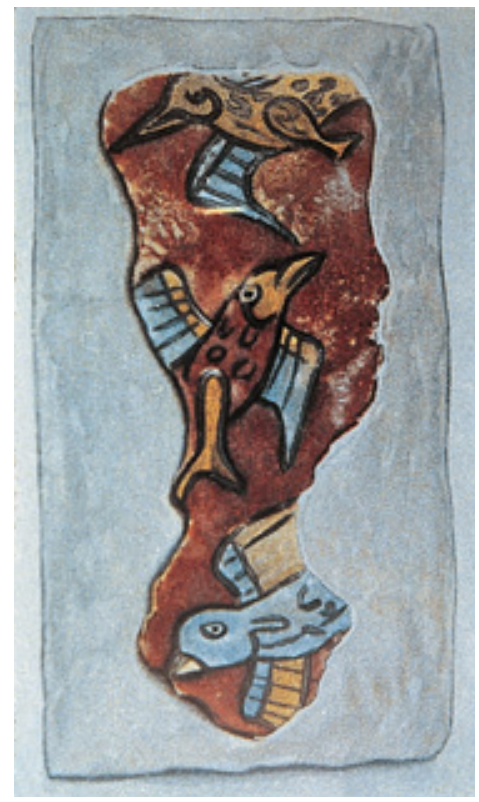

Figuras roa y iob. En el Templo de los Guerreros fueron registrados dos pequeños fragmentos que muestran la figura de seis aves en actitudes de vuelo. Fotos: Archivo Fotográfico IIE-UnAM.

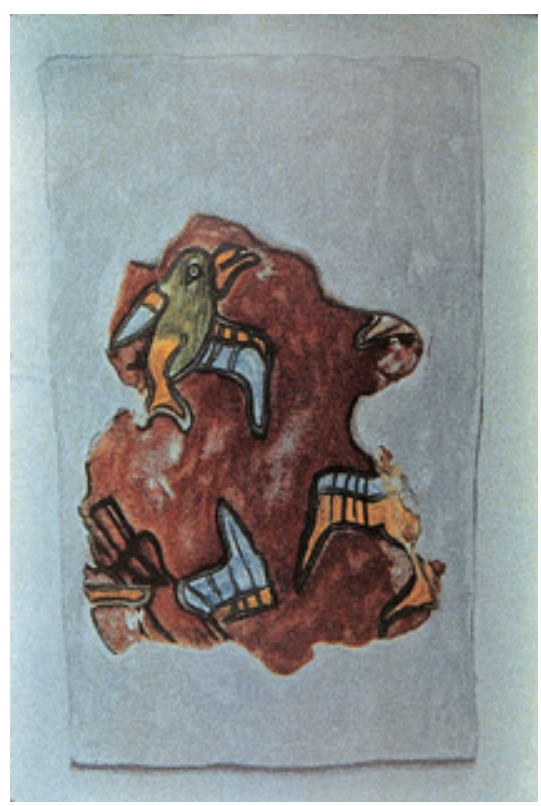


DOI: http://dx.doi.org/10.22201/iie.18703062e.2000.77.1945

22 MARÍA DE LOURDES NAVARIJO ORNELAS

Pese a que las formas son ciertamente burdas, se advierten algunas diferencias en la fisonomía y en el colorido de sus plumajes. Si a estas diferencias se suma su posición, es conjeturable que las seis aves no correspondan a una misma especie. De acuerdo con el análisis de sus semejanzas y diferencias, sólo he podido reconocer a tres de ellas. En uno de los fragmentos (figura Ioa) se encuentran tres aves; de éstas, las dos primeras tienen un parecido con el martín pescador o pescadorcillo (Chloroceryle americana), pues se distingue una coloración verde; la cabeza es grande, y parece tener un copetillo; el pico es largo, recto y fuerte, con aspecto de daga; las alas son redondeadas, y la cola es corta, rasgos que propician la analogía. ${ }^{12}$

En cuanto al aspecto del último integrante del primer fragmento, éste concuerda con el del semillero conocido comúnmente como pico gordo azul (Guiraca caerulea), dado que se observa la cabeza redondeada, un pico grueso y cónico de tono amarillo claro, y una coloración azulosa en cabeza y cuerpo, y las alas pintadas de azul con amarillo; en este caso no se aprecian ni las patas ni la cola. El macho de esta especie es azul oscuro con dos barras castañas en las cobertoras del ala, las que seguramente son las causantes de que en el mural las alas estén pintadas de amarillo.

En el otro fragmento (figura Iob) tenemos un pajarillo regordete de color verde, aparentemente sin cuello, pues no existe una separación o definición entre la cabeza y el cuerpo; las alas terminan en punta, y el diseño es amarillo y blanco como si fueran costillas; la cola termina en una media luna, y es amariIla con la orilla blanca, razones por las que lo encuentro similar a la clorofonia coroniazul (Chlorophonia occipitalis). ${ }^{13}$ La clorofonia es una pequeña ave de selva (II5-I40 mm), de color verde perico brillante, con el pecho y abdomen amarillo canario claro. El pico, que en la representación se observa amarillo con los bordes negros y con la base ancha, y ligeramente curvado, en la tangarita coroniazul es grueso, truncado y de color negro con la base azulada. ${ }^{14}$

En la representación del vuelo, otra modalidad sugerente es la que se encuentra plasmada en el Mural I de la Estructura 86 perteneciente al sitio de Xelhá, en Q uintana Roo. En un mismo mural dividido en dos escenas, se observan dieciocho individuos de psittacidos que presentan diferentes posiciones dinámicas. Por el hecho de que figuran varios individuos de aves de

12. Ibidem.

I3. Ibidem.

I4. Roger Tory Peterson y Edward L. Chalif, Aves de M éxico. Guía de campo, M éxico, Diana, 1989, p. 358. 


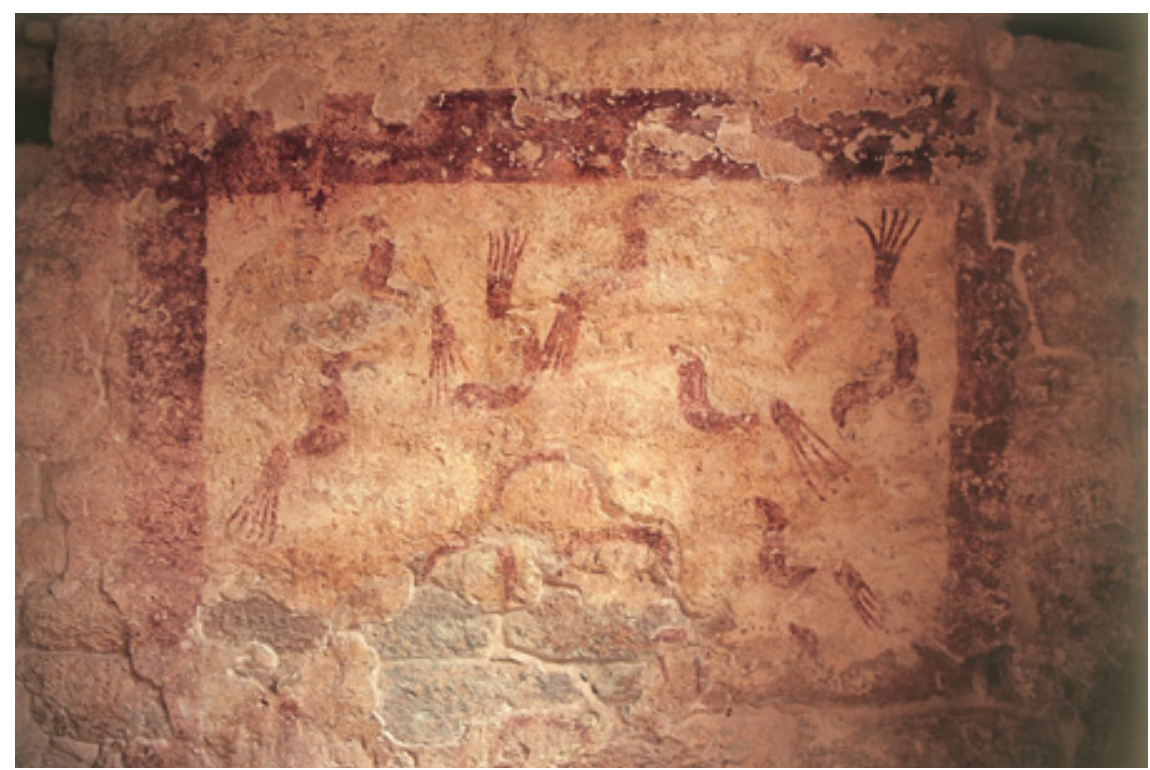

Figura ir. En diferentes posiciones dinámicas vemos a loros y guacamayas rojas en el M ural I de la Estructura 86 en el sitio de Xelhá, Q uintana Roo. Foto: Eduardo A. Cerezo.

dos especies, las escenas se han clasificado en la modalidad in de representación gráfica. En el panel derecho, con referencia al espectador, se tiene a dos aves (los individuos i y 9) que corresponden a representaciones de un loro (Amazona sp.), mientras que las siete aves restantes (posiciones 2, 3, 4, 5, 6, 7 y 8) pertenecen a diseños muy bien captados de la guacamaya roja (Ara macao; figura ir).

En su conjunto las nueve aves del panel derecho se apegan a una imagen real. En particular los cuerpos de las siete guacamayas son grandes y compactos y la cola es notablemente larga, debido al tamaño de las cobertoras. Fue respetada la coloración rojiza del cuerpo y de la cola, ya que esta especie de guacamaya se distingue por su plumaje rojo escarlata, con las cobertoras de las alas amarillas y por tener grandes plumas de vuelo azules. Es distintiva la piel desnuda del área facial, de un tono rosa pálido, que queda insinuada, y los ojos están bien trazados. Por último, como en condiciones naturales, el pico es de aspecto fuerte y ganchudo. ${ }^{\text {Is }}$ 
DOI: http://dx.doi.org/10.22201/iie.18703062e.2000.77.1945

24 MARÍA DE LOURDES NAVARIJO ORNELAS

Para fundamentar una propuesta de interpretación de lo que se observa en el mural, es menester considerar simultáneamente la fisonomía del ave, ciertos patrones propios de la conducta de la guacamaya roja, y recurrir a los contextos históricos.

Por su aspecto llamativo es posible que, en primer lugar, se llegara a establecer un vínculo entre el color rojo escarlata del plumaje y el hecho de que en la distribución cuatripartita del mundo el rojo fuera asignado al punto cardinal del este, siendo el oriente por donde nace el sol. Esta sencilla asociación proporciona bases que justifican el nombre de Guacamaya-deArdiente-Rostro-Solar, que las fuentes documentales del siglo XVI refieren como uno de los varios títulos de la que parece ser una misma deidad. Con frecuencia se identifica a Kinich Kak M 00, "El señor de rostro solar, guacamaya de fuego", con el dios Itzamná, deidad solar. ${ }^{16}$ El concepto de Kinh 0 Kin (Sol-día-tiempo) posee una gran riqueza de connotaciones y evocaciones con variantes zoomorfas.

De acuerdo con la disponibilidad de su alimento, como un segundo punto se tiene que durante el día estas aves se desplazan hacia varias zonas separadas, porque en su dieta están incluidos diversos tipos de frutas, vainas, semillas, nuevos brotes de hojas, flores y de manera ocasional al gunos insectos. Esto hace que las parejas o pequeñas parvadas se muevan día con día entre los sitios de percheo nocturno y los de forrajeo matutino y vespertino. Estos marcados periodos de actividad pudieron ser vistos como modelos de tiempo y espacio y constituir una referencia. En los libros de C hilam Balam, en lo concerniente a los textos de contenido cronológico en la "primera rueda profética de un doblez de katunes", es posible que esa temporalidad pueda ser interpretada a través de la deidad solar "Rostro del Sol, guacamaya de fuego", Kinich Kak M 00, presidiendo y gobernando el periodo de un katún 6-Ahau. ${ }^{17}$ También cabe apuntar que, en las concepciones de Kinh, se ha supuesto que todos los momentos del tiempo son llegadas y presencias de rostros de dioses que se aúnan y apartan de manera sucesiva, dejando sentir sus influencias. ${ }^{18}$

Si a estas especulaciones se suma el asombro que despierta y la importan-

I6. M iguel León-Portilla, Tiempo y realidad en el pensamiento maya, M éxico, Universidad $\mathrm{N}$ acional Autónoma de M éxico, Instituto de Investigaciones H istóricas, 1986, p. 39.

I7. Ibidem, p. 42.

I8. I bidem, p. 59; N avarijo, "Las aves en el mundo maya prehispánico", art. cit. 


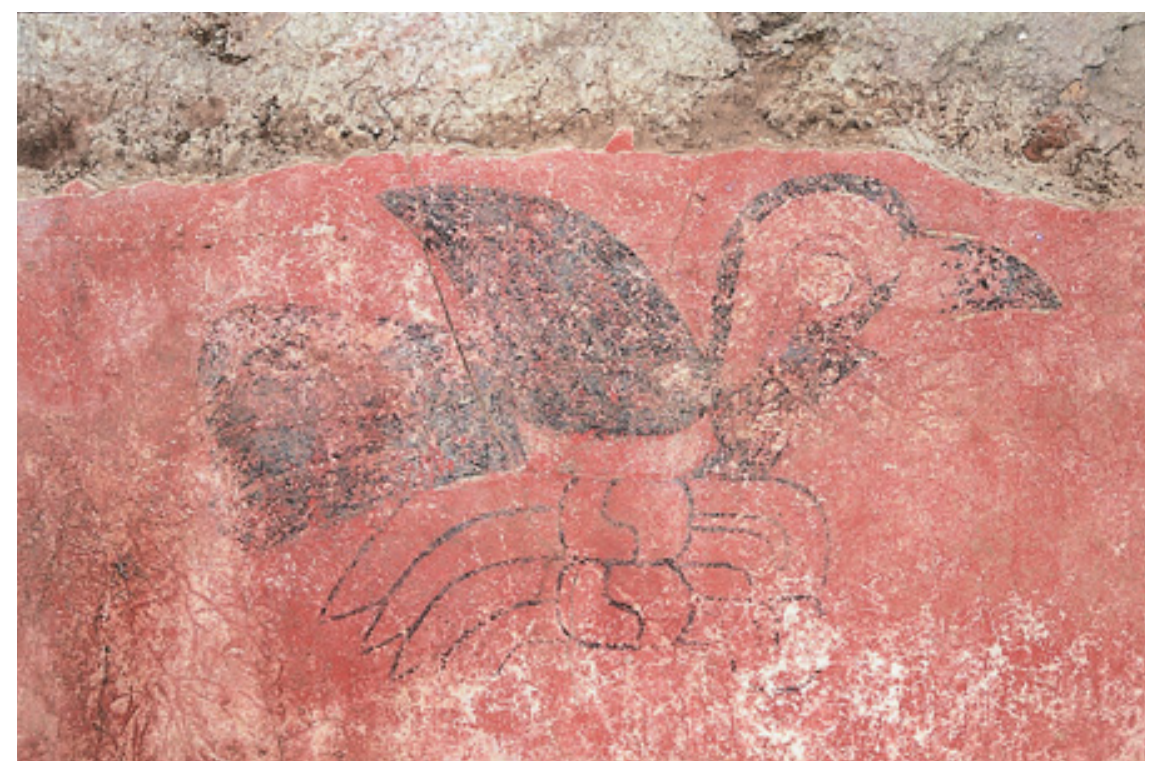

Figura i2. En el Pozo i2 de T otometla se observan individuos del ave conocida comúnmente con el nombre de quebrantahuesos o caracará en ademán de vuelo, transportando un "atado". Foto: Leticia Staines.

cia que ha tenido la capacidad de vuelo de las aves, se podría entonces pensar en que el vuelo y los pronunciados desplazamientos de las guacamayas se conjugaron con la circunstancia de que se trata de aves particularmente ruidosas y gregarias que al perchar agrupadas dan la impresión de una mancha escarlata en continuo movimiento. Por tanto, lo plasmado en el mural Los pájaros puede ser la imagen concreta de una abstracción respecto al tiempo a partir de la realidad conductual observada en las guacamayas y en los loros y de su asociación conceptual con el Sol-día-tiempo.'19

Por último, y bajo otra perspectiva, se puede examinar a las llamadas aves "en procesión" situadas en el Pozo I2, cuadros I-2-3, Y-J-K, en el sitio Purificación-Pirámide llamado también Totometla, en Teotihuacan (figura I2). Estas aves guardan una manifiesta actitud de vuelo que obedece, con seguridad, a la encomienda de transportar por medio de los pies lo que parece ser una especie de "atado". Para efectos de realizar el transporte de manera efi-

19. Ibidem. 
DOI: http://dx.doi.org/10.22201/iie.18703062e.2000.77.1945

26 MARÍA DE LOURDES NAVARIJO ORNELAS

ciente, el ave portadora debe poseer las adaptaciones físicas y los hábitos que contemplen una situación de esta natural eza, ya que gran número de especies utilizan el pico - y no las patas- para asir los objetos en vuelo.

Estas aves delineadas en negro y blanco sobre un fondo rojo presentan una apariencia grande y robusta, y sus rasgos físicos corresponden a los de un ave de presa diurna conocida con el nombre de caracara común o quebrantahuesos (Caracara plancus). ${ }^{20}$ Un grueso trazo negro define el perfil de la cabeza del ave, el cual puede ser atribuido a la intención de diferenciar lo que es la cresta y caperuza café muy oscuro del caracara, cuando no está erecta. También fue reproducido el rostro que es rojizo y parcialmente desnudo, dado que se aprecia esa notable desnudez, sobre todo si se compara con la cola y el ala en las que se conserva un color más oscuro y en las que sí fueron dibujadas las plumas. Además se distingue alrededor del ojo una especie de anillo o banda de color rojo, la que parece que se prolonga hacia el cuello, lo que tal vez sea un artificio para hacer evidente lo rojizo y desnudo del rostro en estado natural. La base del pico se observa amplia y parece fuerte con la punta curvada hacia abajo. La cola es ancha, y un tanto cuadrada y plana, condiciones que están representadas en el mural.

En general, la caracterización de los principales rasgos físicos permite considerar a estas figuras de rapaces como naturalistas, además de que corresponden a la segunda modalidad de representación gráfica y al último nivel de integración temática por ser estas aves el tema central de la escena.

Por medio de estos ejemplos y a manera de recapitulación, se puede afirmar que en la pintura mural prehispánica se encuentra un catálogo importante de especies de aves. Estas especies fueron recreadas con tendencias naturalistas más que simbólicas puesto que, en su gran mayoría, se conservaron ciertos rasgos diagnósticos que permiten reconocerlas con un margen de confiabilidad. Además, el análisis de las escenas ha permitido establecer que las aves estuvieron relacionadas con conceptos y valores de trascendencia cultural que motivaron una asociación particular entre un ave, un evento natural o social y el hombre, lo que en última instancia produjo que las aves se elevaran al rango de objetos culturales al ser las formas de expresión del binomio naturaleza-visión simbólica.s

2o. N avarijo, "La presencia de las aves en la pintura mural teotihuacana”, art. cit. 
Cuadro ı. M odalidades en la representación gráfica e integración temática

\begin{tabular}{|c|c|c|c|c|c|c|c|c|c|c|}
\hline $\begin{array}{c}\text { Especie / } \\
\text { nombre común }\end{array}$ & Localización & & & & & & & & & \\
\hline & & I & II & III & IV & $a$ & $b$ & C & d & $\mathrm{e}$ \\
\hline pelícano café & $\begin{array}{l}\text { Cuarto I o sur, } \\
\text { Estructura I, Xuelén }\end{array}$ & & & $x$ & & & & & $x$ & \\
\hline pelícano & $\begin{array}{l}\text { M ural I, 4-5, } \\
\text { Cuarto I3, Zona 5A, } \\
\text { Teotihuacan }\end{array}$ & & & $\mathbf{x}$ & & & & & $\mathbf{x}$ & \\
\hline cormorán & $\begin{array}{l}\text { Cuarto I o Sur, } \\
\text { Estructura I, Xuelén }\end{array}$ & & & $\mathbf{x}$ & & & & & $\mathbf{x}$ & $\mathbf{x}$ \\
\hline $\begin{array}{l}\text { anhinga } \\
\text { americana }\end{array}$ & $\begin{array}{l}\text { Cuarto I o Sur, } \\
\text { Estructura I, Xuelén }\end{array}$ & & & $\mathbf{x}$ & & & & & $\mathbf{x}$ & $\mathbf{x}$ \\
\hline garza morena & $\begin{array}{l}\text { Templo de los } \\
\text { Guerreros, } \\
\text { Chichén Itzá }\end{array}$ & $\mathbf{x}$ & & & & & & & $\mathbf{x}$ & \\
\hline garza morena & Cuarto 3, Bonampak & $\mathbf{x}$ & & & & & & $\mathbf{x}$ & & \\
\hline zopilote común & $\begin{array}{l}\text { Cuarto i o Sur, } \\
\text { Estructura I, Xuelén }\end{array}$ & & & $\mathbf{x}$ & & & & & $\mathbf{x}$ & $\mathbf{x}$ \\
\hline zopilote aura & $\begin{array}{l}\text { Cuarto 22, } \\
\text { M ural es I-2, } \\
\text { Tetitla, Teotihuacan }\end{array}$ & & $\mathbf{x}$ & & & & & & & $\mathbf{x}$ \\
\hline $\begin{array}{l}\text { águila } \\
\text { pescadora }\end{array}$ & $\begin{array}{l}\text { Cuarto I o Sur } \\
\text { Estructura I, Xuelén }\end{array}$ & & & $\mathbf{x}$ & & & & & $\mathbf{x}$ & $\mathbf{x}$ \\
\hline $\begin{array}{l}\text { milano } \\
\text { coliblanco }\end{array}$ & $\begin{array}{l}\text { Zona basal } \\
\text { exterior, Lado N, } \\
\text { Templo de los } \\
\text { Guerreros }\end{array}$ & $\mathbf{x}$ & & & & & & & $\mathbf{x}$ & \\
\hline águila tirana & Tetitla, Teotihuacan & & $\mathbf{x}$ & & & & & & & $\mathbf{x}$ \\
\hline águilas? & $\begin{array}{l}\text { M urales 2-3, } \\
\text { Pórtico I, Atetelco, } \\
\text { Teotihuacan }\end{array}$ & & $\mathbf{x}$ & & & & & & & $\mathbf{x}$ \\
\hline
\end{tabular}


DOI: http://dx.doi.org/10.22201/iie.18703062e.2000.77.1945

28 MARÍA DE LOURDES NAVARIJO ORNELAS

\begin{tabular}{|c|c|c|c|c|c|c|c|c|c|c|}
\hline $\begin{array}{c}\text { Especie/ } \\
\text { nombre común }\end{array}$ & Localización & & & & & & & & & \\
\hline & & 1 & II & III & IV & $a$ & $b$ & C & $d$ & $\mathrm{e}$ \\
\hline caracara & $\begin{array}{l}\text { Pozo i2, Totometla, } \\
\text { Teotihuacan }\end{array}$ & & $\mathbf{x}$ & & & & & & & $\mathbf{x}$ \\
\hline hocofaisán & Teotihuacan & & & & $x ?$ & & & & $x ?$ & \\
\hline paloma & $\begin{array}{l}\text { M ural 2, Cuarto I, } \\
\text { Plataforma I, Zona 4, } \\
\text { Teotihuacan }\end{array}$ & & & $x$ & & & & & $\mathbf{x}$ & \\
\hline $\begin{array}{l}\text { guacamaya } \\
\text { verde }\end{array}$ & $\begin{array}{l}\text { M ural I, } \\
\text { Corredor I5, Tetitla, } \\
\text { Teotihuacan }\end{array}$ & $\mathbf{x}$ & & & & & & & & $\mathbf{x}$ \\
\hline $\begin{array}{l}\text { guacamaya } \\
\text { verde }\end{array}$ & $\begin{array}{l}\text { Pozo io, Totometla, } \\
\text { Teotihuacan }\end{array}$ & & $x$ & & & & & & & $x$ \\
\hline $\begin{array}{l}\text { guacamaya } \\
\text { roja }\end{array}$ & $\begin{array}{l}\text { Mural I, } \\
\text { Estructura 86, Xelhá }\end{array}$ & & & $x$ & & & & & & $x$ \\
\hline $\begin{array}{l}\text { loro frente } \\
\text { blanca }\end{array}$ & $\begin{array}{l}\text { Subestructura 2, } \\
\text { Q uetzal papál otl, } \\
\text { Teotihuacan }\end{array}$ & & $\mathbf{x}$ & & & & & & & $\mathbf{x}$ \\
\hline loro & $\begin{array}{l}\text { Mural I, } \\
\text { Estructura 86, Xelhá }\end{array}$ & & & $x$ & & & & & & $\mathbf{x}$ \\
\hline búho & $\begin{array}{l}\text { Templo de la } \\
\text { Agricultura, } \\
\text { Teotihuacan }\end{array}$ & $\mathbf{x}$ & & & & & & & $\mathbf{x}$ & \\
\hline búho & $\begin{array}{l}\text { M ural I, Cuarto 27, } \\
\text { Tetitla, Teotihuacan }\end{array}$ & $\mathbf{x}$ & & & & $x$ & & & & \\
\hline $\begin{array}{l}\text { colibrí de } \\
\text { cola hendida }\end{array}$ & $\begin{array}{l}\text { Mural I, } \\
\text { Estructura A, M ulchid }\end{array}$ & $\mathbf{x}$ & & & & & & $\mathbf{x}$ & & \\
\hline colibríes & $\begin{array}{l}\text { Plaza de los G lifos, } \\
\text { La Ventilla, } \\
\text { Teotihuacan }\end{array}$ & & & $\mathbf{x}$ & & & & & $\mathbf{x}$ & \\
\hline $\begin{array}{l}\text { martín } \\
\text { pescador }\end{array}$ & $\begin{array}{l}\text { Templo de los } \\
\text { Guerreros, } \\
\text { Chichén Itzá }\end{array}$ & & & $\mathbf{x}$ & $\mathbf{x}$ & & & & $\mathbf{x}$ & $\mathbf{x}$ \\
\hline
\end{tabular}


DOI: http://dx.doi.org/10.22201/iie.18703062e.2000.77.1945

ARTE Y CIENCIA A TRAVÉS DE LAS IMÁGENES DE AVES

\begin{tabular}{|c|c|c|c|c|c|c|c|c|c|c|}
\hline $\begin{array}{c}\text { Especie / } \\
\text { nombre común }\end{array}$ & Localización & & $\begin{array}{l}\mathrm{Ni} \\
\text { pres }\end{array}$ & $\begin{array}{l}\text { a de } \\
\operatorname{tac}\end{array}$ & & & & & & \\
\hline & & I & II & III & IV & $a$ & $b$ & C & $d$ & $\mathrm{e}$ \\
\hline $\begin{array}{l}\text { clorofonia } \\
\text { coroniazul }\end{array}$ & $\begin{array}{l}\text { Templo de los } \\
\text { Guerreros, } \\
\text { C hichén Itzá }\end{array}$ & & & $x$ & $x$ & & & & $\mathbf{x} ?$ & $\mathbf{x}$ \\
\hline $\begin{array}{l}\text { picogordo } \\
\text { azul }\end{array}$ & $\begin{array}{l}\text { Templo de los } \\
\text { Guerreros, } \\
\text { C hichén Itzá }\end{array}$ & & & $x$ & $x$ & & & & $\mathbf{x} ?$ & $\mathbf{x}$ \\
\hline $\begin{array}{l}\text { aves } \\
\text { fantásticas }\end{array}$ & $\begin{array}{l}\text { Barrio de las } \\
\text { Pinturas Saqueadas, } \\
\text { Teotihuacan }\end{array}$ & & & $x$ & $x$ & & & & $\mathbf{x} ?$ & $x ?$ \\
\hline aves & $\begin{array}{l}\text { M ural 2, Pórtico I3, } \\
\text { Zona 5, Teotihuacan }\end{array}$ & & & $\mathbf{x}$ & & & & & $\mathbf{x}$ & \\
\hline
\end{tabular}

M odalidades en la representación

I. Un solo individuo / una sola especie

II. Dos o más individuos / misma especie

III. Varios individuos / diferentes especies
N iveles de integración temática
a. Como objeto
b. En la vestimenta o como disfraz
c. En los tocados
d. Como individuos que complementan la escena
e. La o las aves son el tema principal 
DOI: http://dx.doi.org/10.22201/iie.18703062e.2000.77.1945

30 MARÍA DE LOURDES NAVARIJO ORNELAS

Cuadro 2. Inventario de especies representadas en la pintura mural prehispánica de Teotihuacan y del área maya

\begin{tabular}{|c|c|c|c|}
\hline \multirow{2}{*}{$\begin{array}{c}\text { TAXA } \\
\text { orden/familia/especie }\end{array}$} & \multirow[t]{2}{*}{ NOM BRE COM ÚN } & \multicolumn{2}{|c|}{ REPRESENTACIÓN } \\
\hline & & $\mathrm{N}$ aturalista & Simbólica \\
\hline \multicolumn{4}{|l|}{ Pelecaniformes } \\
\hline $\begin{array}{l}\text { Pelecanus } \\
\text { occidental is }\end{array}$ & pelícano café & $\mathbf{x}$ & \\
\hline $\begin{array}{l}\text { Pelecanus sp. } \\
\text { Phalacrocoracidae }\end{array}$ & pelícano & $\mathbf{x}$ & \\
\hline $\begin{array}{c}\text { Phalacrocorax } \\
\text { brasilianus }\end{array}$ & $\begin{array}{l}\text { cormorán } \\
\text { oliváceo }\end{array}$ & $\mathbf{x}$ & \\
\hline Anhingidae & & & \\
\hline Anhinga anhinga & anhinga americana & $\mathbf{x}$ & \\
\hline \multicolumn{4}{|l|}{$\begin{array}{l}\text { Ciconiiformes } \\
\text { Ardeidae }\end{array}$} \\
\hline $\begin{array}{l}\text { Ardea H erodias } \\
\text { Cathartidae }\end{array}$ & garza morena & $\mathbf{x}$ & $\mathbf{x}$ \\
\hline Coragyps atratus & zopilote común & $\mathbf{x}$ & \\
\hline Cathartes aura & zopilote aura & $\mathbf{x}$ & \\
\hline \multicolumn{4}{|l|}{ Falconiformes } \\
\hline Accipitridae & & & \\
\hline Pandion haliaetus & águila pescadora & $\mathbf{x}$ & \\
\hline Elanusleucurus & milano coliblanco & $\mathbf{x}$ & \\
\hline $\begin{array}{c}\text { Spizaetus } \\
\text { tyrannus }\end{array}$ & águila tirana & & $\mathbf{x}$ \\
\hline sp. ? & águila & $\mathbf{x}$ & \\
\hline Falconidae & & & \\
\hline Caracara plancus & $\begin{array}{l}\text { quebrantahuesos o } \\
\text { caracara }\end{array}$ & $\mathbf{x}$ & \\
\hline \multicolumn{4}{|l|}{ Galliformes } \\
\hline Crax rubra & hocofaisán & & $\mathbf{x}$ \\
\hline
\end{tabular}




\begin{tabular}{|c|c|c|c|}
\hline TAXA & NOM BRE COMÚN & REPRES & $\overline{A C I O N}$ \\
\hline orden/familia/especie & & Naturalista & Simbólica \\
\hline $\begin{array}{c}\text { Columbiformes } \\
\text { Columbidae } \\
\text { Columba sp. } \\
\text { Zenaida sp. }\end{array}$ & $\begin{array}{l}\text { paloma } \\
\text { paloma }\end{array}$ & $\begin{array}{l}\mathbf{x} \\
\mathbf{x}\end{array}$ & \\
\hline $\begin{array}{l}\text { Psittaciformes } \\
\text { Psittacidae } \\
\text { Ara militaris } \\
\text { Ara macao } \\
\text { Amazona } \\
\text { albifrons } \\
\text { Amazona sp. }\end{array}$ & $\begin{array}{l}\text { guacamaya verde } \\
\text { guacamaya roja } \\
\text { loro frente blanca } \\
\text { loro }\end{array}$ & $\begin{array}{l}\mathbf{x} \\
\mathbf{x} \\
\mathbf{x} \\
\mathbf{x}\end{array}$ & \\
\hline $\begin{array}{l}\text { Strigiformes } \\
\text { Strigidae } \\
\text { sp. } \\
\text { sp. }\end{array}$ & $\begin{array}{l}\text { búho } \\
\text { búho }\end{array}$ & & $\begin{array}{l}\mathbf{x} \\
\mathbf{x}\end{array}$ \\
\hline $\begin{array}{l}\text { Apodiformes } \\
\text { Trochilidae } \\
\text { D oricha eliza } \\
\text { sp.? }\end{array}$ & $\begin{array}{l}\text { colibrí eliza o } \\
\text { de cola hendida } \\
\text { colibrí }\end{array}$ & $\begin{array}{l}\mathbf{x} \\
\mathbf{x}\end{array}$ & \\
\hline $\begin{array}{c}\text { Coraciiformes } \\
\text { Alcedinidae } \\
\text { Chloroceryle } \\
\text { americana }\end{array}$ & martín pescador & $\mathbf{x}$ & \\
\hline $\begin{array}{l}\text { Passeriformes } \\
\text { Thraupidae } \\
\text { Chlorofonia } \\
\text { occipitalis } \\
\text { Cardinalidae } \\
\text { Guiraca caerulea }\end{array}$ & $\begin{array}{l}\text { clorofonia } \\
\text { coroniazul } \\
\text { picogordo azul }\end{array}$ & $\mathbf{x}$ & \\
\hline $\begin{array}{l}\text { sp. } \\
\text { sp. ? }\end{array}$ & $\begin{array}{l}\text { aves fantásticas } \\
\text { avecillas }\end{array}$ & $\mathbf{x}$ & $\mathbf{x}$ \\
\hline
\end{tabular}

Total = Io órdenes, 15 familias, 28 especies 
DOI: http://dx.doi.org/10.22201/iie.18703062e.2000.77.1945

32 MARÍA DE LOURDES NAVARIJO ORNELAS

\section{Bibliografía}

Álvarez del Toro, M iguel, Las aves de Chiapas, T uxtla Gutiérrez, Universidad Autónoma de Chiapas, 1980.

Bent, Arthur Clevaland, Life H istories of N orth America Petrels and Pelicans and their Allies, N ueva York, D over Publications, I964.

Foncerrada de M olina, M arta, "La representación de pájaros en el arte teotihuacano", en Anales del Instituto de Investigaciones Estéticas, vol. Xv, núm. 57, M éxico, 1989, pp. 7-22.

León-Portilla, M iguel, T iempo y realidad en el pensamiento maya, M éxico, U niversidad $\mathrm{N}$ acional Autónoma de M éxico, Instituto de Investigaciones $\mathrm{H}$ istóricas, 1986.

M orris, Earl H. et al., The Temple of the Warriors at Chichén Itzá, Yucatán, W ashington, Carnegie Institution of W ashington, 193I, 2 vols.

N avarijo, Lourdes, "Por qué es de utilidad conocer la identidad de las aves representadas en la pintura mural prehispánica", en Coloquio Cantos de M esoamérica. M etodologías científicas en la búsqueda del conocimiento prehispánico, M éxico, U niversidad N acional Autónoma de M éxico, Instituto de Astronomía, Facultad de Ciencias, I995, pp. 315-322. , "La presencia de las aves en la pintura mural teotihuacana", en La pintura mural pre hispánica en M éxico, M éxico, U niversidad N acional Autónoma de M éxico, Instituto de Investigaciones Estéticas, I996, vol. I, T eotihuacan, t. II, Estudios, pp. 325-34I.

, "Las aves en el mundo maya prehispánico", en La pintura mural prehispánica en M éxico, M éxico, U niversidad N acional Autónoma de M éxico, Instituto de Investigaciones Estéticas, vol. II, Área maya, t. III, Estudios, 200I, pp. 22I-253.

Peterson, Roger Tory y Edward L. Chalif, Aves de M éxico. Guía de campo, M éxico, Diana, 1989.

Šégota, D úrdica, Valores plásticos del arte mexica, M éxico, U niversidad $\mathrm{N}$ acional Autónoma de M éxico, Instituto de Investigaciones Estéticas, 1995.

Trabulse, Elías, Arte y ciencia en la historia de M éxico, M éxico, Fomento Cultural Banamex, I995. 